Macromolecular Symposia

WILEY

\title{
Synergistic sorption of mixed solvents in wood cell walls: experimental and theoretical approach
}

\begin{tabular}{|r|l|}
\hline Journal: & Macromolecular Symposia \\
\hline Manuscript ID & masy.201900022.R1 \\
\hline Wiley - Manuscript type: & Full Paper \\
\hline Author: & n/a \\
\hline Complete List of Authors: & $\begin{array}{l}\text { Aguilera-Segura, Sonia Milena; Institut Charles Gerhardt } \\
\text { Bossu, Julie; Institut Charles Gerhardt; Ecole des Mines d'Ales } \\
\text { Trens, Philippe; Institut Charles Gerhardt } \\
\text { Mineva, Tzonka; Institut Charles Gerhardt } \\
\text { Di Renzo, Francesco; Institut Charles Gerhardt } \\
\text { Le Moigne, Nicolas; Ecole des Mines d'Ales } \\
\text { Corn, Stephane; Ecole des Mines d'Ales }\end{array}$ \\
\hline Keywords: & $\begin{array}{l}\text { composite materials, mixed solvents, sorption isotherms, viscoelastic } \\
\text { properties, molecular dynamics }\end{array}$ \\
\hline
\end{tabular}

\section{SCHOLARONE \\ Manuscripts}




\title{
Synergistic sorption of mixed solvents in wood cell walls:
}

\section{experimental and theoretical approach}

\author{
Sonia Milena Aguilera-Segura, Julie Bossu, Stéphane Corn, Philippe Trens, Tzonka Mineva, \\ Nicolas Le Moigne*, Francesco Di Renzo*
}

S. M. Aguilera-Segura, Dr. J. Bossu, Prof. P. Trens, Dr. T. Mineva, Dr. F. Di Renzo

Institut Charles Gerhardt, UMR 5253 UM-CNRS-ENSCM, ENSCM, 240 Avenue Emile Jeanbrau, 34296 Montpellier Cedex 05, France

direnzo@enscm.fr

Dr. S. Corn, Dr. N. Le Moigne

C2MA, IMT Mines Ales, Université de Montpellier, 6 avenue de Clavières 30319, Alès, France

nicolas.le-moigne@mines-ales.fr

Keywords: composite materials, mixed solvents, sorption isotherms, viscoelastic properties, molecular dynamics

\begin{abstract}
The behavior of poplar wood and its components in water-ethanol mixtures is investigated through a coupled experimental and theoretical approach including physico-chemical and dynamic mechanical analyses and molecular dynamics simulations. Affinity for water-ethanol vapors, measured by isothermal gravimetric sorption experiments, features a maximum for mixed vapors. The longitudinal viscoelastic behavior of the same wood upon immersion in ethanol-water solutions, measured by dynamic mechanical analysis, features a minimum in storage modulus and a maximum damping upon immersion in solutions of intermediate composition. Optical microscopy observation of solvent-saturated samples evidences interand intra-cellular disbonding in pure ethanol and ethanol aqueous solutions. Molecular dynamics simulations provide information on interactions of water-ethanol solutions with models of cellulose microfibers and lignin. The relative solvation of cellulose microfibers by water and ethanol shows a nearly linear variation with the composition of the solution. In contrast, the accessibility of lignin dimers to the solvent presents a maximum at intermediate ethanol concentrations, in correspondence with a conformational transition of the dimer towards an extended conformation. The modelisation of the interactions of cellulose and lignin in water-ethanol solutions indicates a minimum of adhesion of the two components of wood in the presence of solutions with intermediate concentrations.
\end{abstract}

\section{Introduction}




\section{WILEY-VCH}

How does the exposure to solvents affect the mechanical and chemical stability of composite materials? The rise of polymer composites as structural materials in all technological fields justifies a more and more general interest to the question. Indeed, the same synergy of properties which is at the basis of the interest of composite materials multiplies possible weak points, especially at the interfaces between components, where specific interactions and sensitivity to solvents can bring to loss of cohesion detrimental for macroscopic properties of the composite.

More complex occurrences can be observed when composite materials are exposed to mixed solvents. A typical instance of the technological problems implied has been observed with the introduction of oxygenates in transportation fuels, with the consequent exposition of the rich variety of materials of vehicle engines to a mix of solvents with different polarities. Some elastomers had to be banned from fuel-exposed components as, for instance, polyurethanes underwent a three times larger swelling in methanol-gasoline blends than in the neat liquids. ${ }^{[1]}$ In the case of fiber-reinforced resin fuel tanks, a test fuel blend of octane, toluene and methanol was found to produce much more swelling, surface crazing and cracking than the component solvents alone. ${ }^{[2]}$ The microstructure of the composite materials can significantly tune the solvent effects, as it was observed in the case of conducting carbon sensors embedded in polymer matrices, when the trend of variation of the composite conductivity with the composition of swelling solvent blends was inverted according to the level of the electrical percolation point of the material. ${ }^{[3]}$

Which effects can be expected when mixed solvents interact not with artificial composites but with wood, the most widespread natural composite, whose cell walls structure is a complex hierarchical assembly of biopolymers and biomolecules with different polarity? Swelling by solvents is an important technological parameter for wood, either for its deconstruction and further use of its different components in biobased chemistry, or for its use as structural material (timber or wood-polymer composites), often implying the penetration of additives and preservatives.

Non-linear evolution of the mechanical properties of wood with the composition of mixed solvent solutions has early been noticed. Robertson observed that binary mixtures of liquids can produce more swelling than each component alone and that this synergistic effect is particularly pronounced when water is one of the liquids. ${ }^{[4]}$ Later, O'Leary and Hodges mentioned that such systems behave "strangely" and reported that preferential adsorption of certain components within binary systems can cause disproportionate tangential swelling.[5] In this study, we would like to address the specific case of water-ethanol solutions, which are 


\section{WILEY-VCH}

involved in a large range of industrial uses. Studying poplar and pinewood in green and dry conditions, Chang et al. and Meier et al. reported that water-ethanol solutions generate "hyperswelling", namely a swelling more important than that observed for either pure water or pure ethanol. ${ }^{[6-8]}$ More precisely, the most important deformations were reported for a $50 \%$ volume fraction of ethanol. Similar results were observed on gels of acetylated lignin, showing no swelling in ethanol but eight times the initial volume for swelling in water/ethanol $50 \%{ }^{[9]}$

The sorption of solvents does not only alter the mass and volume of the material but also strongly affects its mechanical properties. Alteration of both tensile and shear strength of bamboo fibers composites has been evidenced upon aqueous treatments with ethanol.[10-11] Alterations in stress transfer mechanisms within cell walls and between wood cells in the presence of solvents are probably related to selective extraction of some components of cell walls and middle lamellae. Resulting modifications of the physico-mechanical and hygroscopic properties of lignocellulosic fibers have been monitored by Meier, who reported that ethanol-water mixtures generate local intercellular decohesion. ${ }^{[12,13]}$ Studies on other lignocellulosic materials also identified specific effects of the cooperative sorption of water and organics on middle lamellae and different layers of primary and secondary cell walls. ${ }^{[14]}$ In the study of the behavior of (ligno-)cellulosic fibers in aqueous solutions of NMMO $(\mathrm{N}$ methylmorpholine $N$-oxide), Le Moigne et al. observed gradients in swelling and dissolution mechanisms between the different cell walls, related to variations in their biochemical composition. ${ }^{[15,16]}$ Acera Fernández et al. and Lefeuvre et al. showed that the removal of noncellulosic components from the cell walls of flax fibers with various aqueous and organic solvents could strongly affect the transverse mechanical properties of the fibers and their composites. ${ }^{[17,18]}$

To unravel the underlying mechanism of non-linear effects of mixed solvents on wood structure, we attempted a two-prongs approach including experimental monitoring of the change of properties of poplar samples upon sorption of given amount of solutions or vapors and a theoretical chemistry modelisation of the interaction of primary wood components with mixed solvents. In the experimental approach, poplar was chosen as a model wood material due to its low extractive content, thus preventing the issues related to solubility of lowmolecular weight components. Non treated veneers from poplar sapwood were used to produce identical sample replicas. The progress of sorption of water-ethanol vapors as a function of the relative pressure was monitored by isothermal gravimetric sorption and provided information on the affinity of mixed vapors for the material. The effect of saturation 


\section{WILEY-VCH}

of wood by the solvents on viscoelastic properties and wood cell structure was studied by operando dynamic mechanical analysis and optical microscopy, respectively. Molecular dynamics (MD) simulations were carried out to model the interaction of water-ethanol mixed systems with the main wood components, cellulose and lignin.

\section{Results and discussion}

\subsection{Sorption isotherms of water-ethanol vapours on poplar veneer}

Sorption isotherms of vapor at the equilibrium with water, ethanol and an aqueous ethanol solution are represented in Figure 1A. The water vapor isotherm, with the sorption of nearly $16 \%$ water at $\mathrm{p} / \mathrm{p}^{\circ} 95$, is typical of wood moisture sorption. ${ }^{[14]}$ The shape of the isotherm has often suggested its classification as a type IV IUPAC isotherm, typical of mesoporous solids. However, the hysteresis loop of condensation in mesopores should have a lower limit at the relative pressure at which capillary tension in the mesopore meniscus exceeds the tensile strength of the condensed liquid. ${ }^{[19]}$ The continuation of the hysteresis loop to relative pressure lower than 0.31 , the limit value for water, indicates that sorption is not taking place by surface adsorption and pore condensation but by absorption in the material of the cell walls $[20]$
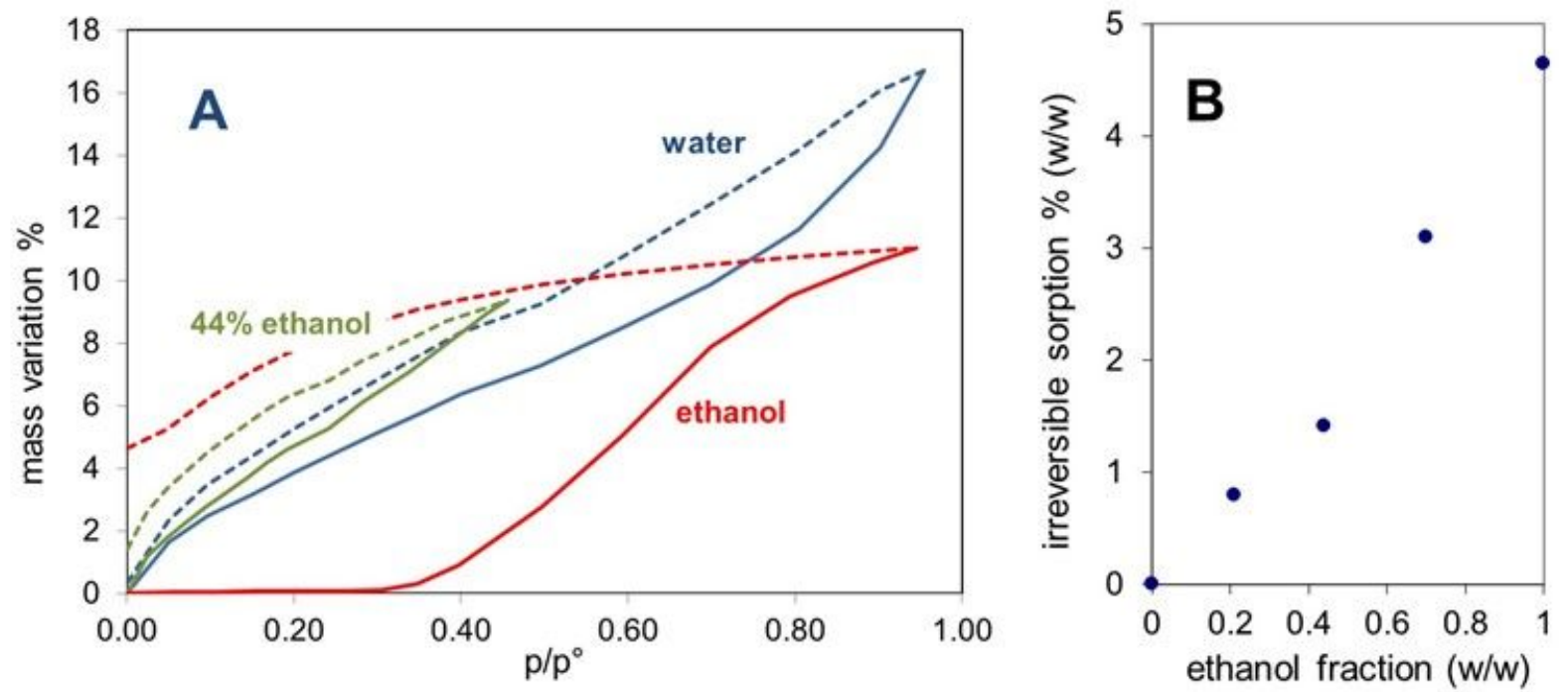

Figure 1. Sorption isotherms of water, ethanol and $44 \mathrm{wt} \%$ ethanol aqueous solution on poplar wood (A) and irreversible sorption as a function of the ethanol fraction in aqueous solution $(B)$.

The sorption isotherm of ethanol vapour follows a very different pattern and features a sigmoidal shape with an important delay of uptake. Sorption begins only at $\mathrm{p} / \mathrm{p}^{\circ}$ higher than 


\section{WILEY-VCH}

0.3 , indicating an activation energy barrier for the penetration of methanol in the material. The desorption curve presents a broad hysteresis and a significant amount of sorbate is retained also at $\mathrm{p} / \mathrm{p}^{\circ}=0$, when no more ethanol vapour can be measured. The sorption isotherm of the vapour at the equilibrium with a $44 \% \mathrm{w} / \mathrm{w}$ aqueous ethanol solution do not present any delay of uptake and features a shape similar to the water isotherm, albeit with a higher uptake at any given relative pressure. Moreover, some irreversible retention of sorbate is observed at the end of the desorption. The irreversibly-sorbed amount has been measured at the end of sorption loops for different concentrations of ethanol in solution (see Figure 1B) and is roughly proportional to the concentration of ethanol.

The different sorption behavior of water and ethanol can be globally interpreted by assuming an important role of the heterogeneity of the wood material. Water is clearly absorbed at very low partial pressure, showing a high affinity for the cell walls. The delayed sorption of ethanol can be interpreted as a more difficult penetration in the wood cell walls, which has to be related to their specific chemical composition and microstructure. Once the activity of ethanol is large enough, the molecule can go across the cell walls and favourable sorption in the bulk of the material is observed. In the case of water-ethanol mixtures, the sorption of water allows the sorption of ethanol at lower partial pressure, indicating that the water-sodden cell walls become more permeable to ethanol. The proportionality of the irreversible retention of sorbate with the concentration of ethanol strongly suggests chemisorption of ethanol in the bulk of the material.

\subsection{Viscoelastic behavior of poplar veneer in water-ethanol solvents}

The main properties measured by mechanical testing of viscoelastic materials are storage modulus E', corresponding to the elastic energy stored in the material under test, and damping $\tan \delta$, corresponding to the ratio between the viscous energy dissipated as heat and the stored energy. ${ }^{[21]}$ The evolution of these parameters upon immersion in water, ethanol and $44 \mathrm{wt} \%$ ethanol aqueous solution are reported in Figure 2. Saturation of poplar veneer with any solution brings to decrease of storage modulus and increase of damping. However, the nature of the solvent highly affects the extent of these variations. Immersion in water brings to much larger decrease of storage modulus and increase of damping than immersion in ethanol. In the case of water, damping passes through a maximum at 5.5 times the initial value before decreasing to equilibrium values nearly $35 \%$ lower, whereas the lower values observed for ethanol are quite stable on a longer time. The decrease of damping after the transient maximum in water is accompanied by a slight recovery of $E^{\prime}$. 


\section{WILEY-VCH}
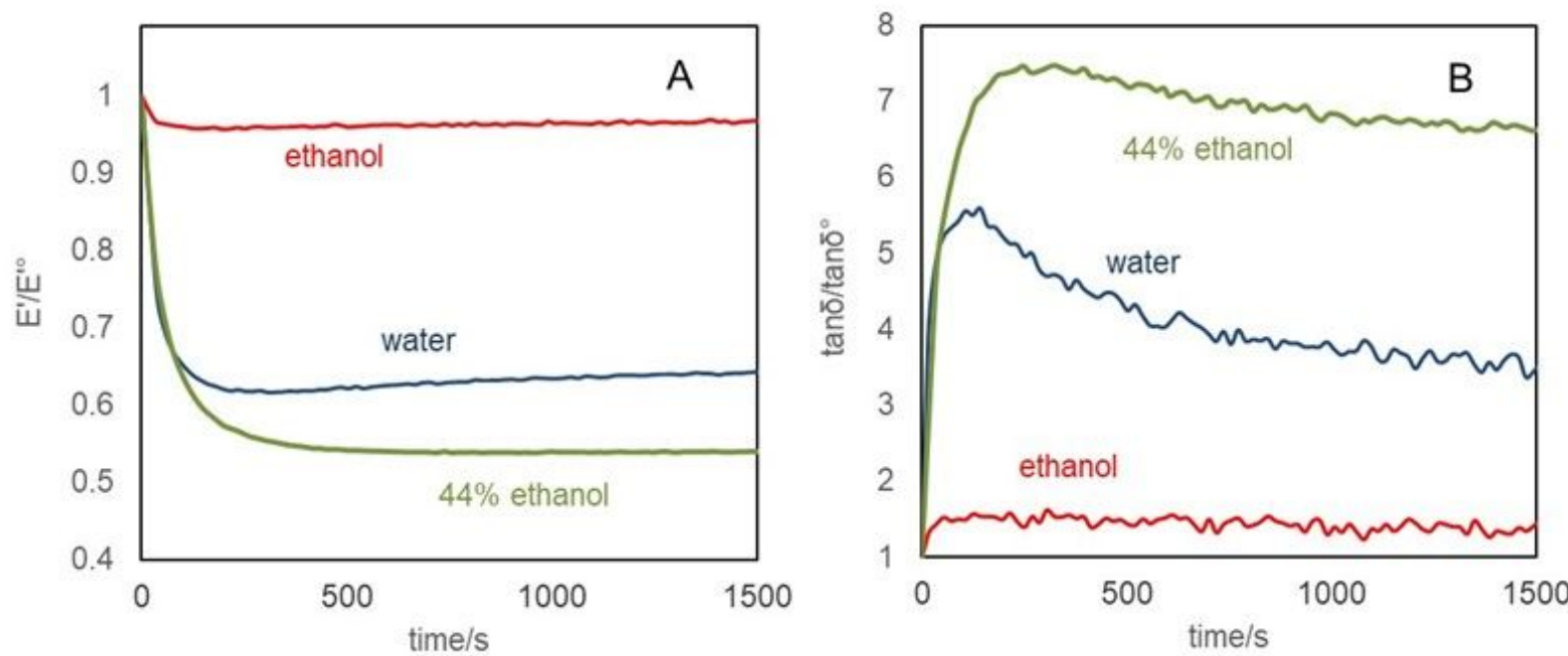

Figure 2. Viscoelastic properties of poplar veneers specimens immersed in water. ethanol and $44 \%$ ethanol aqueous solution. Evolution of relative storage modulus (A) and relative damping (B) after immersion at $\mathrm{t}^{\circ}$.

The strong variations in viscoelastic behavior observed for water saturation has been attributed to the diffusion of water molecules within the secondary cell wall, i.e. the main body of cell walls, at the origin of stiffness and longitudinal strength of wood. ${ }^{[22]}$ Navi et al. showed that the transient hydrogen bonding between crystalline cellulose and the surrounding amorphous polymers, owed to the introduction or removal of water, may accelerate shear slip between the two phases in the presence of an external load. ${ }^{[23]}$ Meier et al., working with different loading modes, already suggested that sorption of ethanol entails lower modifications of the mechanical properties than water. ${ }^{[13]}$ The large difference between mechanical properties after immersion in water or ethanol contrasts with the reasonably similar amounts of water and ethanol absorbed at saturation in the isothermal gravimetric sorption experiments. If ethanol molecules were absorbed within cell wall layers at the same absorption sites as water molecules, their larger steric hindrance would generate more swelling and higher modifications in viscoelastic behavior than water sorption, contrary to observed evidence. On these bases, it is assumed that the absorption sites of water and ethanol and the nature of their interactions with wood biopolymers are different and do not play the same role in the resulting viscoelastic behavior of poplar wood.

The variation of mechanical parameters upon immersion in water-ethanol solutions are not a linear combination of the effects observed for pure water and ethanol. Indeed, the observed decrease in storage modulus and increase in damping are higher than those observed with pure water (Figure 2). Some trends of mechanical properties upon saturation can be related to effects observed in sorption behavior (Figure 1). The observed order of relative E' decrease 


\section{WILEY-VCH}

and $\tan \delta$ increase, mixed solvent $>$ water $>>$ ethanol, corresponds to the ranking of initial slopes of the sorption isotherms, itself related to the affinity of the solvents for the material. The extent of decrease of damping after a transient peak follows instead the order water $<$ mixed solvent $<<$ ethanol and can be related to the extent of irreversible retention of sorbate at the end of the desorption isotherm. The gradual decrease in relative $\tan \delta$ after reaching extreme variations corresponds to a rearrangement of sorbate molecules and/or related relaxation processes of biopolymers within the wood structure after initial swelling. The penetration of ethanol molecules in the material seems to slow down the entire process of desorption and re-equilibration after sorption. A possible mechanistic interpretation of these results could be that irreversibly absorbed ethanol molecules modified the pristine microstructure of wood cells and/or their intercellular cohesion.

\subsection{Optical microscopy of water-ethanol sodden poplar veneer}

Slices of $25 \mu \mathrm{m}$ thickness were sampled from specimens used for dynamic mechanical analysis in water, ethanol or mixed solvents, to be observed by optical microscopy (Figure 3). Wood cells from the sample immersed in water (Figure 3A) are tightly packed against each other and show thick cell walls.
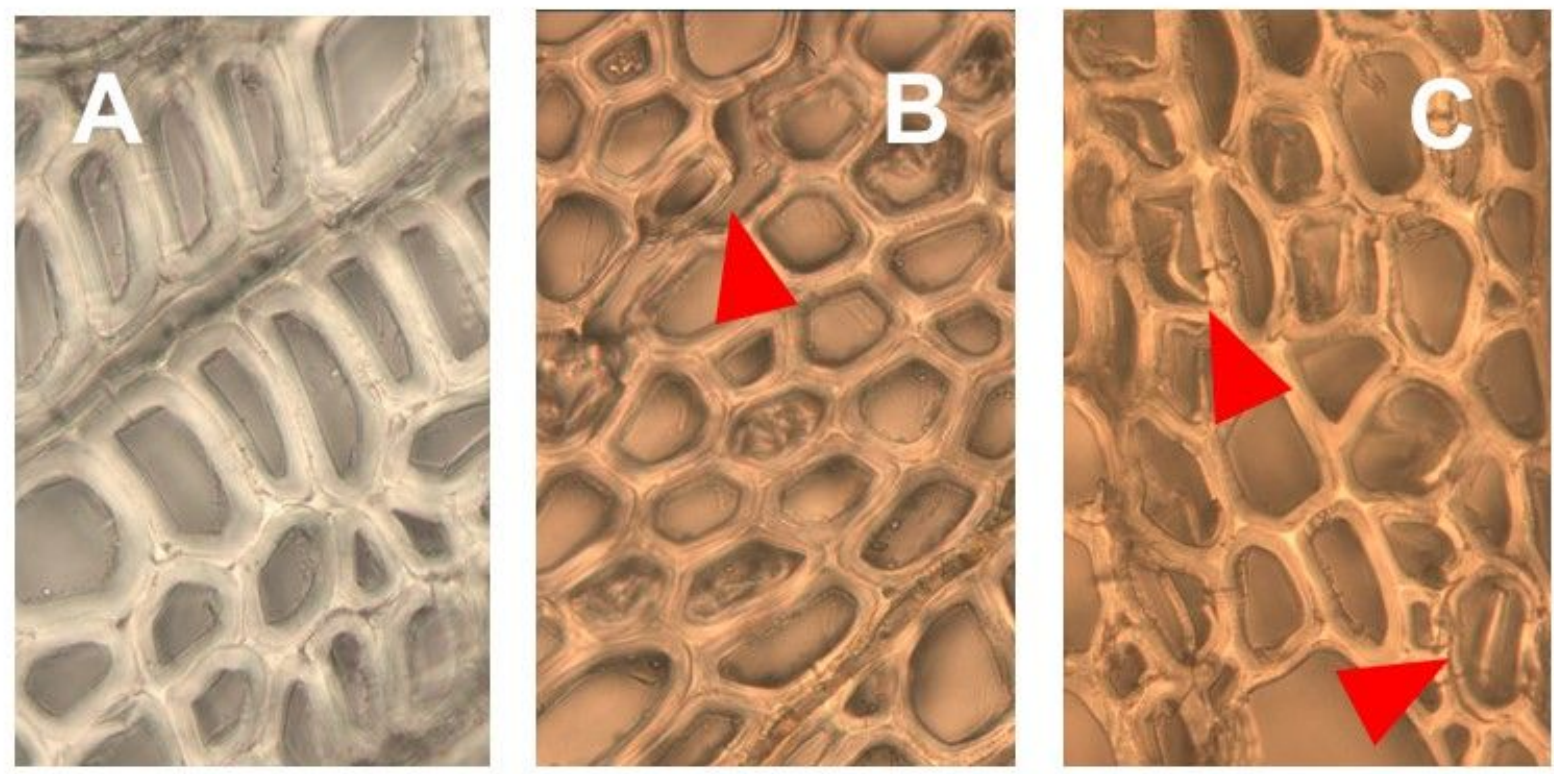

Figure 3. Cross-sections of poplar veneer immersed in water (A), $44 \mathrm{wt} \%$ ethanol aqueous solution (B) and absolute ethanol (C). Width of each picture is $100 \mu \mathrm{m}$. Red arrows highlight intercellular decohesion in $\mathrm{B}$ and interlayer disbonding in $\mathrm{C}$.

The cell walls are compact and well bound to the middle lamella, the continuous lignin-rich phase which connects cell walls through the tissues. On the contrary, in ethanol (Figure 3C), 


\section{WILEY-VCH}

cell walls swell to a lower extent, in agreement with previous reports. ${ }^{[14,24]}$ In addition, after saturation with ethanol, primary wall (the cell wall layer nearer to the middle lamella) seems less bounded to the middle lamella, where peeling can be observed, suggesting that intercellular decohesion occurred in ethanol. It also appears that ethanol absorption can entail disbonding within the cell walls, i.e. intracellular decohesion between the cell wall layers. These phenomena can be the result of the weakening of interfaces between and within the cell walls, and can be related to previous observations by Meier et al. on disbonding in pinewood swollen in ethanol or by Clair et al. on the detachment of the G-layer in the case of poplar tension wood. ${ }^{[8,25]}$

Vapor sorption measurements have already shown that ethanol might be preferentially absorbed by lignin rather than cellulose. ${ }^{[26]}$ The middle lamella, which is mainly composed of lignin and other phenolic compounds, might then preferentially interact with ethanol, being altered or even partially dissolved. This could explain the disbonding between primary wall and middle lamella. Within the secondary wall (viz. the wall layers nearest to the cell lumen), external layers contain greater amounts of lignin, and can thus possibly disbond from the others.

In water-ethanol mixed solvent (Figure 3B), a combination of high swelling due to water and intercellular decohesion due to ethanol can be observed. After immersion in $44 \mathrm{wt} \%$ ethanol aqueous solution, both high swelling of the secondary wall and frequent local disbonding between the middle lamella and the primary wall can indeed be noticed. Non-linearity effects of aqueous solution of organics have already been observed in papermaking, where aqueous solutions of ethanol and acetone led to higher lignin solubilization and extraction of polyphenols than pure solvents. ${ }^{[27,28]}$

The coupling of water sorption and intercellular disbonding by ethanol appears to be the best combination to maximize microscopic swelling of wood cells. Indeed, in this situation, cells are less mutually constrained and the cell walls swell more freely. If ethanol reacts preferentially in lignin-rich regions as the middle lamella and the outer parts of the cell walls, it is also likely that pre-swelling by water enables ethanol to get access to these sites. This hypothesis is also supported by works of Hosseinpourpia et al. and Yang et al., who observed that the removal of lignin from pinewood samples allows higher water absorption and stronger swelling of the polysaccharide matrix. ${ }^{[29,30]}$

\subsection{Elaboration of model structures of cellulose and lignin}

The possibility of a detachment between lignin-rich middle lamella and cellulose-rich cell wall 


\section{WILEY-VCH}

upon impregnation of wood by mixed solvents supported the need for a modelisation of the effects of water-ethanol solvents on the interactions between the surfaces of cellulose and lignin. The first step was the determination of adequate models for these two main wood components. A model of truncated cellulose crystal (cellulose nano-crystallyte) was built with seven cellulose chains, eight-monomers long (56 anhydroglucose units, Figure 4A), using the crystallographic structure of cellulose I $\beta$ reported by Nishiyama et al. and built with the cellulose-builder tool of Gomes and Skaf. ${ }^{[31,32]}$ Oxygen terminal residues were capped with hydrogen atoms and carbon terminal residues were capped with $\mathrm{OH}$ groups to obtain a finite chain. The model reproduces correctly the intramolecular and intermolecular hydrogen bond patterns expected for cellulose I $\beta$ chains. ${ }^{[33]}$ Despite the limitation of our computational analyses due to the small size of the model, some information can be drawn on the more hydrophobic or hydrophilic behavior of different chains. The hydroxymethyl groups of cellulose chains BDEG (Figure 4A) remain mainly buried inside the nanocrystal during the simulations, therefore these chains display a more hydrophobic behavior than cellulose chains $\mathrm{AF}$, whose hydroxymethyl groups stand exposed to the surface.

A lignin dimer formed by two guaiacyl (G) monomer units (Figure 4B) was drawn including a $\beta-O-4$ linkage, the most frequent linkage found in natural lignin. In order to study the lignincellulose interactions, we modelled the assembly of the cellulose nanofiber model with 4 lignin dimers, one at each surface, as illustrated in Figure 4C. Each lignin dimer was placed close to the cellulose surface, at a distance below $2 \AA$ of the atomic centre of the closest atom, in order to favour the initial cellulose-lignin interactions. The cellulose/lignin models were centred in cubic boxes, leaving at least $1 \mathrm{~nm}$ to the longest side of the model to avoid interactions between cellulose/lignin model and its images in the neighbouring boxes. This rim spacing was used to determine the size of the box. Each cellulose/lignin system was further solvated with the number of solvent molecules needed to fill the box size, as summarized in the experimental section. 


\section{WILEY-VCH}

A) cellulose
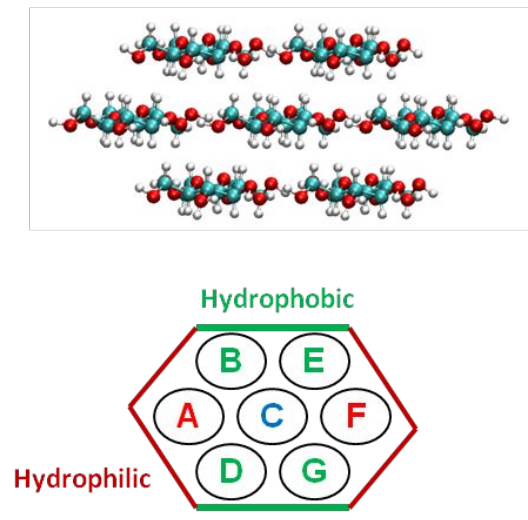

B) lignin

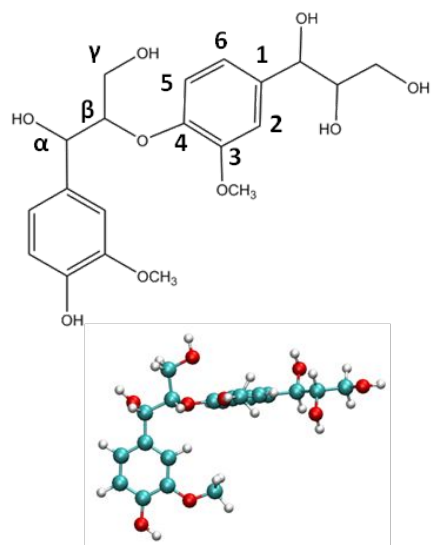

C) cellulose-lignin

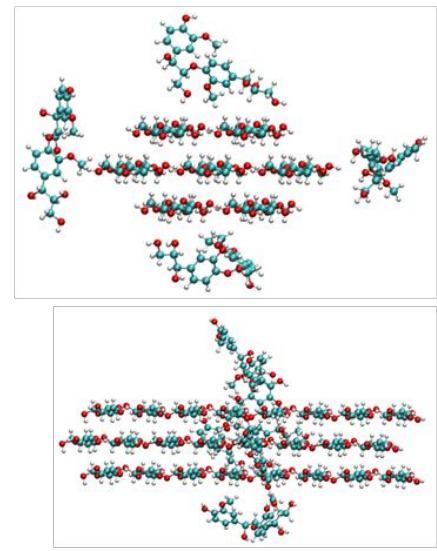

Figure 4. (A) Cellulose nanocrystal model with 7 chains (ABCDEFG). Chains BDEG represent the hydrophobic surface and chains AF represent the hydrophilic surface. Color code: oxygen (red), hydrogen (white), and carbon (cyan). (B) Lignin model: G-G dimer with $\beta-O-4$ linkage. Top: schematic representation and atom notation. Down: optimized structure in gas phase from quantum-chemistry DFT-PBE calculations. (C) Cellulose-lignin assembly. Top: front view; down: lateral view.

\subsection{Modelling the interaction of water-ethanol solvents with a cellulose nanocrystal}

The cellullose solvation is described by the radial distribution function (rdf), that describes the number of particles at distance $r$ from a reference site. Due to the amphiphilic nature of cellulose chains in our model, we examined separetely the hydrophobic and hydrophilic surfaces labeled as BDEG and AF chains, respectively, in Figure 4. The $\mathrm{O}_{\text {cellulose }}-\mathrm{O}_{\text {solvent }} \mathrm{g}(r) \mathrm{s}$ describe well-structured solvation layers at both hydrophilic and hydrophobic surfaces, in agreement with previous cellulose-water rdf studies. ${ }^{[34]}$ The integration of $\mathrm{g}(r)$ from 0 to $r$, $\mathrm{cn}(r)$, gives the cumulative number of particles within a distance $r$ from the cellulose surface atoms. The computed $\mathrm{cn}(r)$ of water and ethanol molecules within $r=0.7 \mathrm{~nm}$ from the glycosidic oxygen of cellulose, $\mathrm{O}_{4}$, as a function of ethanol concentration, are summarized in Figure 5. The number of water molecules surrounding the cellulose surfaces (Figure 5A) decreases with cosolvent concentration, as a result of the water displacement by ethanol. 


\section{WILEY-VCH}
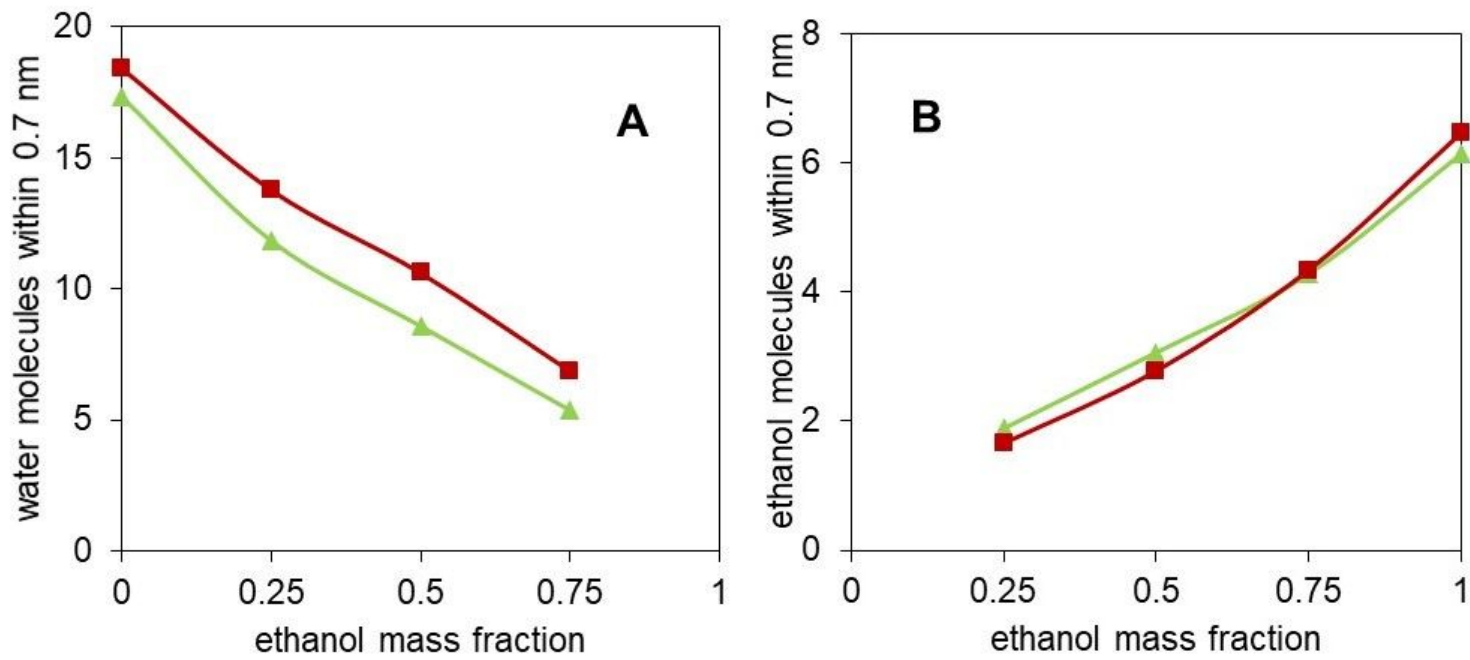

Figure 5. Cumulative number (cn) of molecules of water(A) and ethanol (B) within $0.7 \mathrm{~nm}$ from the cellulose glycosidic oxygen, as a function of ethanol concentration. Green triangles: hydrophobic surface (chains BEDG); red squares: hydrophilic surface (chains AF).

Moreover, water molecules are always more abundant around the hydrophilic surface than on the hydrophobic surface of cellulose. Correspondingly, in Figure 5B, the number of ethanol molecules surrounding the surface increases with the solvent concentration. At low ethanol fraction, there is a slight preference of ethanol for hydrophobic surface, due to competition with water. However, beyond $75 \%$ ethanol, an inversion of the $\mathrm{cn}(r)$ is observed, in which more ethanol molecules are found near the hydrophilic than the hydrophobic cellulose surface, suggesting an amphiphilic behaviour of ethanol. This effect is most likely due to the reconstruction of the $\mathrm{H}$-bond network of the ethanol solvent, less disrupted by the remaining water molecules. We note that, keeping in mind that the volume of a $\mathrm{H}_{2} \mathrm{O}$ molecule is about $1 / 3$ of the volume of an ethanol molecule, at $100 \%$ ethanol concentration approximately three water molecules should be replaced by ethanol. Our analysis in Fig. 5, indeed, indicates that nearly 2.8 water molecules are replaced by one ethanol molecule.

The intermolecular cellulose-water and cellulose-ethanol hydrogen bonds (HBs) in each water-ethanol system are summarized in Figure 6A and 6B. The cellulose-water interactions play the major contribution to the intermolecular hydrogen bonding and more cellulose-water HBs are found on the hydrophilic surfaces than on the hydrophobic surfaces. The cellulosewater HBs in alcohol-water systems linearly decrease with the ethanol concentration, as a response to water displacement due to alcohol competition for H-bonding sites, as can be inferred from the cellulose-ethanol HBs in Figure 6B. The frequency of cellulose intramolecular H-bonds (Figure 6C) slightly increases from water to aqueous solutions of ethanol and strongly increases for pure ethanol. This suggests that, in the absence of strong 


\section{WILEY-VCH}

interactions with water, the surface cellulose chains are reoriented towards the core of the nanocrystal increasing the cohesion of the sub-surface layer.
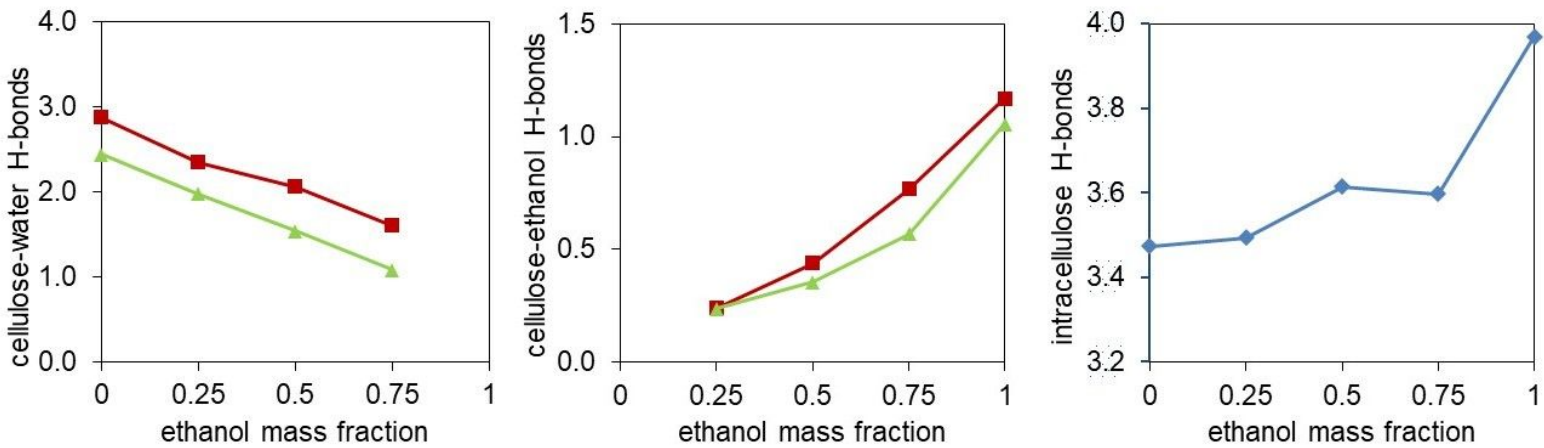

Figure 6. Average number of hydrogen bonds (HBs) per anhydroglucose monomer between cellulose and water (A) or cellulose and ethanol (B) at different ethanol concentrations. Green triangles: hydrophobic surface (chains BEDG); red squares: hydrophilic surface (chains AF). Average number of cellulose intra-molecular HBs per anhydroglucose monomer $(\mathrm{C})$ at different ethanol concentrations.

\subsection{Dynamics of lignin model dimer in water-ethanol solvents}

MD simulations of a lignin dimer in pure water, ethanol and ethanol-water mixtures allow to calculate the distribution of the solvent accessible surface area (SASA). It can be observed in Figure 7A that, in water and the most ethanol-poor mixed solution, the lignin dimers display the lowest average SASA, as a hydrophobic response of the lignin dimer towards water, a bad solvent for lignin.
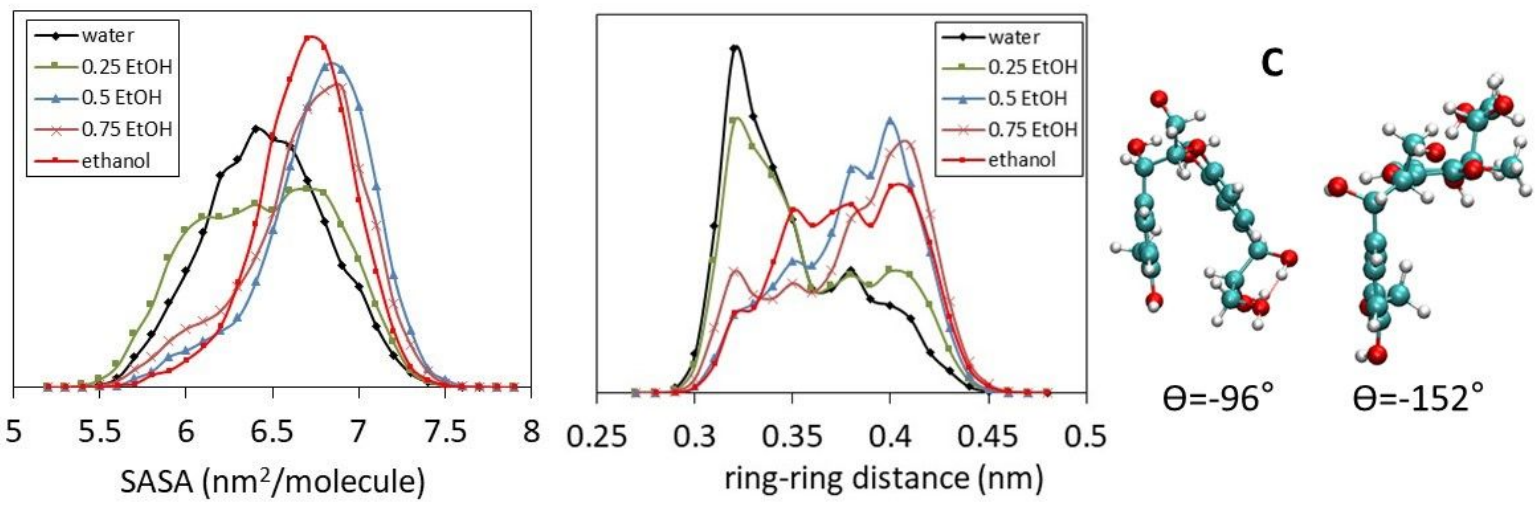

Figure 7. Distributions of solvent accessible surface area, SASA, of lignin model at different ethanol concentrations (A). Center-of-mass ring-ring distance distribution of guaiacyl monomers at different ethanol concentrations (B). Model lignin conformers (C) with different solvent accessibility and ring-ring coupling depending on the dihedral torsion angle $\theta=\mathrm{C}_{4^{-}}{ }^{-}$ $\mathrm{O}^{\prime}{ }_{4}-\mathrm{C}_{8}-\mathrm{C}_{7}(\mathrm{C})$. Conformers with $\theta=-96^{\circ}$ are found mostly in water and diluted ethanol mixture, whereas conformers with $\theta=-152^{\circ}$ are predominant in $50-75 \mathrm{wt} \%$ mixtures and pure ethanol.

In pure ethanol, the surface increases as the interactions between the solvent and the lignin improve. However, it is in the range of the mixed solvent composition where the largest 


\section{WILEY-VCH}

accessible surface is found. This effect corresponds to a change of conformation of the lignin dimer, which assumes a more extended conformation, corresponding to a higher interaction with the solvent. The distribution of the distance between the two aromatic rings of the guaiacyl dimer, shown in Figure 7B, indicates the presence of a stacked conformation with ring-ring distance at $0.32 \mathrm{~nm}$, predominant in water and $0.25 \%$ ethanol. A less stacked conformer with a ring-ring distance close to $0.40 \mathrm{~nm}$ is dominant in ethanol and ethanol-rich mixtures. The torsion angle of the dimer $\theta(\theta=\mathrm{C} 4$ '-O4-C $\beta-\mathrm{C} \alpha)$ shows a dihedral conformation distribution near $\theta=-96^{\circ}$ in pure water and diluted ethanol (Figure $7 \mathrm{C}$ ). For the pure ethanol and concentrated mixtures, the dihedral conformation is mostly found near $\theta=-152^{\circ}$. Furthermore, the angle distribution near $-152^{\circ}$ is narrower in $75 \%$ ethanol solution than in pure ethanol. This effect is in qualitative agreement with the results of Smith et al., who studied the conformation of lignin polymers of up to 60 units in water-tetrahydrofuran (THF) mixtures. ${ }^{[35]}$ In their study, they found that mixed solvents facilitate the solvation of lignin molecules, which, instead, in pure water adopt a crumbled globular-like shape, with a considerably reduced SASA. Additionally, very recent studies of lignin solubility in waterethanol mixtures have identified a solubilisation maximum at $60 \mathrm{wt} \%$ ethanol.[36]

\subsection{Modelling the cellulose-lignin interactions in water-ethanol solvents}

Molecular dynamics of a model of cellulose and four lignin dimers in the same simulation box provided some information on the effect of solvent on the physical adhesion between cellulose and lignin. The cellulose-lignin intermolecular energies reported in Figure 8 are weaker in mixed solvents.

This simulation suggests that a detachment between cellulose and lignin, an important phenomenon in the separation of cellulose and dissolved lignin in pulping processes, is favoured in the presence of mixed solvents. It is interesting to compare the relative intensity of Van der Waals and electrostatic interactions. Van der Waals interactions modelled with the Lennard-Jones potential are stronger than Coulomb energies (Figure 8). The similar behaviour of the Lennard-Jones and Coulomb energy curves in the mixed solvent region indicates that these two types of interactions are highly correlated. 


\section{WILEY-VCH}

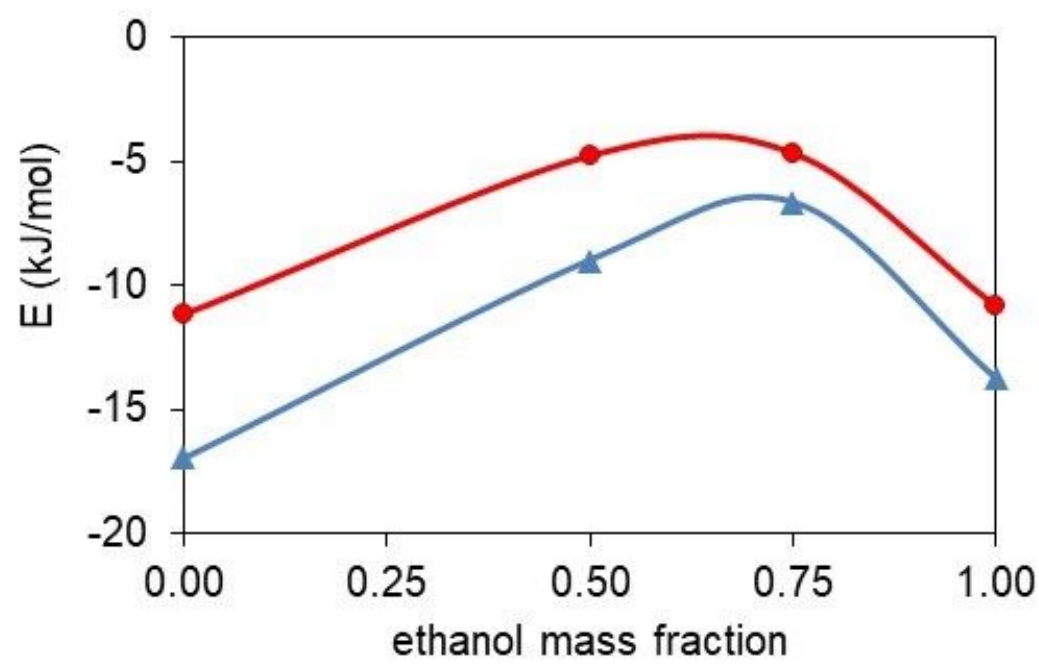

Figure 8. Lennard-Jones (blue triangles) and Coulomb (red circles) energies of lignincellulose molecular interaction normalized on number of lignin dimers in the system vs. composition of water-ethanol solutions.

Despite Lennard-Jones energy is predominant, the electrostatic interactions also bring an important contribution, which can be better evaluated by the evolution of hydrogen bonds between cellulose and lignin with the composition of the solvent. The H-bond probability distribution describes the probability of finding lignin bound to cellulose $(H-b o n d \geq 1)$ or unbounded $(\mathrm{H}-$ bond $=0)$. Moreover, a high probability at $\mathrm{H}$-bond $=0$ is a good descriptor of the capacity of the solvent of disturbing the lignin-cellulose electrostatic interactions, favouring the unbound system. Given the hydrophobic nature of lignin, we show the cellulose-lignin $\mathrm{H}$ bond probability distribution with the cellulose hydrophobic surface (Figure 9).

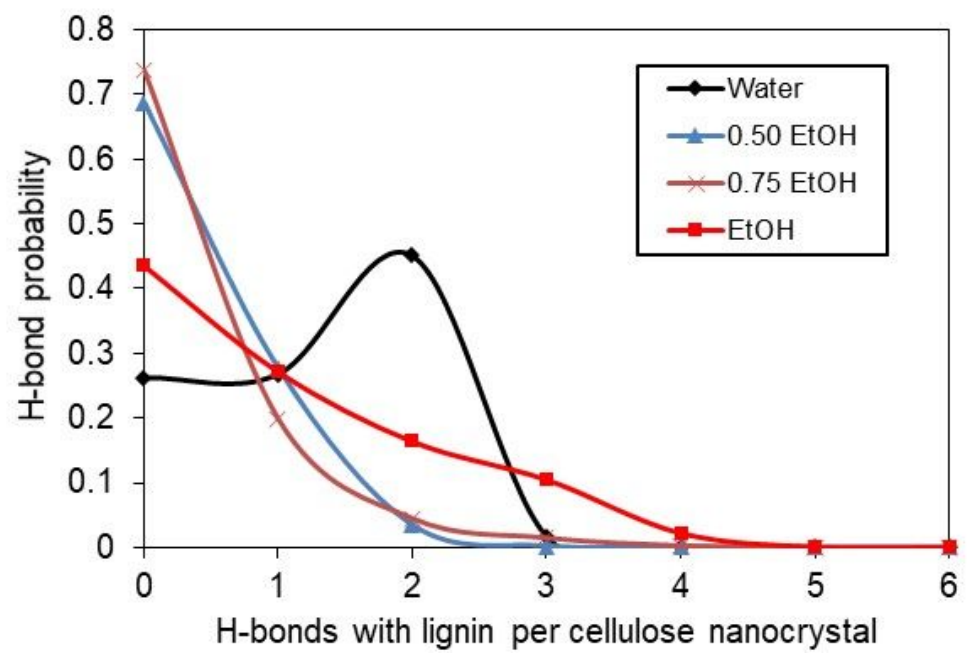

Figure 9. Probability distribution of hydrogen bonds between lignin dimers and hydrophobic cellulose chains (BDEG) in pure and aqueous ethanol mixtures. Lines are added to help the reader's eye despite the H-bond intervals being discrete. 


\section{WILEY-VCH}

In water alone, the probability distribution falls around H-bond $=2$. Thus, our results show that in water (a bad solvent for lignin) the adhesion of lignin to cellulose is favoured. In pure ethanol, the higher probability falls at $\mathrm{H}$-bond $=0$, favouring the unbound state of lignin, but also an important part of the distribution falls at the bounded state. Nevertheless, the H-bond distribution confirms that water-ethanol mixture enhances lignin dissolution, as the unbound state is favoured with the highest probability for the mixed water-ethanol solutions.

\section{Conclusions}

The study of the interaction of poplar wood and its components with water-ethanol solutions and their vapors confirms that wood is an effective model for the study of the peculiar behavior of composite materials exposed to mixed solvents. Two kinds of non-linearity play a role in the behavior of composite materials exposed to mixed solvents: (i) the colligative properties of ethanol aqueous solutions are themselves not linear with their composition; ${ }^{[37]}$ (ii) moreover, the differential interactions of each component of the solvent with specific components of the composite material creates further non-linearity of the sorption and mechanical properties of the material.

Several instances of "hyperswelling" of wood in the ethanol-water system can be observed, namely an effect of mixed solution exceeding the linear combination of the effects observed with individual solvent components. The affinity of the material for the solvent, proportional to the initial slope of the sorption isotherms, increases in the order ethanol $<<$ water $<$ ethanol-water solution, confirming a synergistic effect of water and ethanol. The amount of solvent absorbed is an important property, strictly related to the swelling of the material. Also, considering the viscoelastic properties, storage modulus decreases and damping increases in the order ethanol $<<$ water $<$ ethanol-water solution, attesting for higher softening in the case of ethanol-water mixtures. Optical microscopy observations after saturation of wood by the mixed solvents indicate that the differential affinity of the components of the solvent within wood microstructure plays a significant role in the phenomena. Partial dissolution of specific zones, possibly lignin-rich regions, within wood microstructure can favour the release of constraints within and between the cell walls, and can allow more free swelling of hydrophilic polysaccharide-rich zones.

Molecular dynamics have proved effective in simulating the non-linear effects of solvent solutions on wood components. Once established the relative affinities of water and ethanol for cellulose (more hydrophilic) and lignin (less hydrophilic), non-linear effects have been observed in the solvation of lignin, which reaches a maximum between $50 \%$ ethanol aqueous 


\section{WILEY-VCH}

solution and pure ethanol. The simulation of a cellulose-lignin complex has indicated that the magnitude of interactions between the two wood components follows the order water $>$ ethanol $>$ ethanol-water solution. The decrease of lignin-cellulose interaction in mixed solvents can play a significant role in the purification of cellulose from dissolved lignin in organosolv pulping processes.

\section{Experimental section}

\subsection{Materials and experimental methods}

Never-dried and untreated poplar veneers (Populus tremula) were cut with a hydraulic press in the sapwood zone along fibers direction ( $\mathrm{R} 5 \mathrm{~mm}, \mathrm{~T}=0.5 \mathrm{~mm}, \mathrm{~L}=45 \mathrm{~mm})$ and stabilized for 2 months at $25^{\circ} \mathrm{C} ; 45 \% \mathrm{RH}$.

Vapor sorption measurements were performed at $40{ }^{\circ} \mathrm{C}$ by dynamic vapor sorption (DVS) in an isothermal gravimetric sorption instrument (DVS-Vacuum, Surface Measurement Systems). Each wood specimen was loaded and dried in-situ at $40{ }^{\circ} \mathrm{C}$ under high vacuum $(2 \times$ $10^{-6}$ Torr) for $10 \mathrm{~h}$ before admission of vapor in successive steps of increasing and decreasing relative pressure $\left(\mathrm{p} / \mathrm{p}^{\circ}\right)$.

The effects of solvent sorption on the dynamic longitudinal mechanical behavior of wood specimens were analyzed by coupling a Dynamic Mechanical Analyzer (DMA) (50N Metravib) with a tank connected to a thermostatic bath regulated at $40{ }^{\circ} \mathrm{C}$. Samples were mounted in tensile mode before being immersed in the solvent bath. The variations of the complex modulus $\mathrm{E}^{*}$, which is composed of the storage modulus $\mathrm{E}^{\prime}$ (real part) and loss modulus E" (imaginary part), and the damping $\left(\tan \delta=E^{\prime \prime} / E^{\prime}\right)$ were measured at a frequency of $0.05 \mathrm{~Hz}$ all along the absorption process. After mechanical testing, each sample was cut into thin radial slices of $25 \mu \mathrm{m}$ thickness with a WSL GSL1 sledge microtome. The slices, stored in the same solution, were placed between two glass plates and the cell walls were observed with a Leica DM LM/P optical microscope in transmission mode.

\subsection{Molecular dynamics simulation methods}

All-atom MD simulations of each system described in Table 1 were carried out using the GROMACS package 2016.3, ${ }^{[38-42]}$ along with the 4-sites Transferable Intermolecular Potential (TIP4) for liquid water, ${ }^{[43-45]}$ the CHARMM36 additive force field, ${ }^{[46,47]}$ and the CHARMMcompatible force field for lignin. ${ }^{[48]}$ Solvent structure for ethanol was available at the GROMACS molecule and liquid database. ${ }^{[49]}$ Each cellulose/lignin model was centered in a 


\section{WILEY-VCH}

cubic box and each macromolecule-solvent system was solvated with the number of solvent molecules dictated by the volume of the box, as summarized in Table $\mathbf{1}$.

Table 1. Configuration of simulated systems and equilibrium size of simulation boxes for cellulose nanocrystal ( 7 chains, 8 glucose monomers each) and lignin models studied in this work

\begin{tabular}{|c|c|c|c|c|c|c|}
\hline $\begin{array}{c}\text { Model wood } \\
\text { component }\end{array}$ & $\begin{array}{c}\text { Solvent } \\
\text { system }\end{array}$ & $\begin{array}{c}\text { Ethanol } \\
\text { fraction } \\
(\mathrm{wt} \%)\end{array}$ & $\begin{array}{c}\text { Number of } \\
\text { ethanol } \\
\text { molecules }\end{array}$ & $\begin{array}{c}\text { Number of } \\
\text { water } \\
\text { molecules }\end{array}$ & $\begin{array}{c}\text { Cubic box } \\
\text { side length } \\
(\mathrm{nm})\end{array}$ & $\begin{array}{c}\text { Volume } \\
(\mathrm{nm} 3)\end{array}$ \\
\hline \multirow{2}{*}{$\begin{array}{c}\text { Cellulose } \\
\text { nanocrystal } \\
(7 \text { chains, } 56 \\
\text { glucose } \\
\text { monomers })\end{array}$} & ethanol-water & 0 & 0 & 9764 & 6.739 & 306.03 \\
\cline { 2 - 7 } & pure ethanol & 100 & 4321 & 0 & 7.547 & 429.92 \\
\cline { 2 - 7 } & pure water & 0 & 0 & 1448 & 3.54 & 44.55 \\
\cline { 2 - 7 } & & 25 & 132 & 1012 & 3.515 & 43.45 \\
\hline \multirow{4}{*}{$\begin{array}{c}\text { Lignin G-G } \\
\beta-O-4 \text { dimer }\end{array}$} & ethanol-water & 50 & 250 & 641 & 3.514 & 43.41 \\
\cline { 2 - 7 } & & 75 & 355 & 302 & 3.51 & 43.55 \\
\cline { 2 - 7 } & pure ethanol & 100 & 399 & 0 & 3.4 & 39.48 \\
\hline \multirow{2}{*}{$\begin{array}{c}\text { Cellulose } \\
\text { nanocrystal }+ \\
4 \text { lignin } \\
\text { dimers }\end{array}$} & pure water & 0 & 0 & 10370 & 6.886 & 326.56 \\
\cline { 2 - 7 } & ethanol-water & 50 & 1725 & 4415 & 6.749 & 307.46 \\
\cline { 2 - 7 } & pure ethanol & 75 & 2443 & 2084 & 6.749 & 307.48 \\
\hline
\end{tabular}

For each simulation box, energy minimization was performed using the steepest descent algorithm until convergence to a tolerance of $100 \mathrm{~kJ} \mathrm{~mol}^{-1} \mathrm{~nm}^{-1}$. After minimization, restrained simulations were performed for 200 ps at $298.15 \mathrm{~K}$. Afterwards, 20-ns MD simulations were performed with a frame-saving rate (for analysis) of $1 \mathrm{ps}$, in order to study the interaction of the cellulose/lignin models with the solvent molecules. Temperature and pressure coupling were handled using the leap-frog stochastic dynamics integrator and the Parrinello-Rahman method, respectively. Initial velocities were generated from a Maxwell distribution at $298.15 \mathrm{~K}$ and the isothermal-isobaric (NPT) ensemble was consider for data collection. Neighbor searching and short-range non-bonded interactions were handled with the Verlet cut-off scheme. Electrostatics were treated with the Fast smooth Particle-Mesh Ewald (SPME) method, with a Coulomb cut-off of $1.2 \mathrm{~nm}$, a fourth order interpolation and Fourier spacing of $0.12 \mathrm{~nm}$. Van der Waals (vdW) interactions were treated using the Lennard-Jones potential with a cut-off distance of $1.2 \mathrm{~nm}$. Simulations were carried out in an Intel Xeon CPU with $2.10 \mathrm{Gz}$ with 32 logical cores

The structure and dynamics of the macromolecules in the water-ethanol mixtures were characterized by site-to-site radial distribution functions $\mathrm{g}(\mathrm{r})$, cumulative numbers $\mathrm{cn}(\mathrm{r})$, 


\section{WILEY-VCH}

average number of hydrogen bonds (HBs), solvent accessible surface area (SASA), and intermolecular energies using the incorporated tools within GROMACS. Each of these descriptors was calculated for all the water-ethanol concentrations considered in this study. Site-to-site $\mathrm{g}(\mathrm{r}) \mathrm{s}$ were computed for the water-macromolecule and ethanol-macromolecule pairs using the oxygens of water, ethanol, cellulose and lignin. Cumulative numbers were obtained from the integration of the $\mathrm{g}(\mathrm{r})$ up to a $2 \mathrm{~nm}$ correlation distance. HBs were calculated using a geometrical criterion with a maximum donor-acceptor distance of $0.35 \mathrm{~nm}$ and a hydrogen-donor-acceptor angle of $30^{\circ}$, and they were accordingly further normalized, as described in the text. Solvent accessible surfaces were computed using the double cubic lattice method (DCLM) by using a solvent probe radius of $0.14 \mathrm{~nm}$. Further details of the MD simulations and the description of the tools used for analysis can be found in our previous work on water-ethanol mixture interactions. ${ }^{[37]}$

\section{Acknowledgments}

This work was partially funded by the Agence Nationale de la Recherche program Investissements d'Avenir through the contract ANR-10-LABX-05-01 (LabExCheMISyst) and by an ENSCM PhD grant in the framework of the SINCHEM Joint Doctorate program under the Erasmus Mundus Action 1 Programme (FPA 2013-0037). Access to the HPC resources of CCRT/CINES/IDRIS was granted under the allocation x2017087369 by GENCI. Poplar veneers were graciously provided by Maurice Orly, Danzer Company. The authors acknowledge the support of Surface Management Systems London and their team for DVS analyses, the technical support of Marc Longerey, Centre des Matériaux des Mines d'Alès (C2MA), for dynamic mechanical measurements and the assistance of Olivier Arnoult, Laboratoire de Mécanique et Génie Civil (LMGC) of the Université de Montpellier, in microscopy techniques.

Received: ((will be filled in by the editorial staff))

Revised: ((will be filled in by the editorial staff)) Published online: ((will be filled in by the editorial staff))

\section{References}

[1] R. L. Bechtold, M. B. Goodman, T. A. Timbario. Use of Methanol as a Transportation Fuel, The Methanol Institute, Arlington, VA, USA 2007.

[2] L. S. Norwood, Chemical resistance of composites, https://netcomposites.com/guidetools/guide/coatings/chemical-resistance/, accessed December 2018.

[3] S. Frackowiak, M. Maciejewska, A. Szczurek, M. Kozlowski. e-Polymers 2011, 032.

[4] A. A. Robertson. Pulp Paper Mag Canada 1964, 65, 171.

[5] P. O'Leary, P. A. Hodges. Wood Sci Technol 2001, 35, 217.

[6] S. Chang, B. Clair, J. Gril, H. Yamamoto, F. Quignard. Wood Sci Technol 2009, 43, 703. 


\section{WILEY-VCH}

[7] S. Chang, F. Quignard, F. Di Renzo, B. Clair. BioResources 2012, 7, 2418.

[8] P. Meier, T. Kaps, U. Kallavus. Mater Sci Medzg 2005, 11,140.

[9] M. Nishida, Y. Uraki, Y. Sano. Bioresour Technol 2003, 88, 81.

[10] Y. A. Hu, M. He, R. X. Zhu, Y. H. Zhang, Y. L. Yu, W. J. Yu. J Trop For Sci 2016, 28, 112

[11] L. Qin, W. J. Yu. Adv Mater Res 2009, 79,1395.

[12] P. Meier, U. Kallavus, A. Rohumaa, T. Kaps. Mater Sci Medzg 2006, 12, 25.

[13] P. Meier, E. Stöör, T. Kaps, U. Kallavus. Est J Eng 2006, 12, 125.

[14] J. Bossu, N. Le Moigne, S. Corn, P. Trens, F. Di Renzo. Wood Sci Technol 2018, 52, 987.

[15] N. Le Moigne, E. Montes, C. Pannetier, H. Höfte, P. Navard. Macromol Symp 2008, 262, 65.

[16] N. Le Moigne, J. Bikard, P. Navard. Cellulose 2010, 17, 507.

[17] J. Acera Fernández, N. Le Moigne, A. S. Caro-Bretelle, R. El Hage, A. Le Duc, M. Lozachmeur, P. Bono, A. Bergeret. Ind Crops Prod 2016, 85, 93.

[18] A. Lefeuvre, A. Le Duigou, A. Bourmaud, A. Kervoelen, C. Morvan, C. Baley, Ind. Crops Prod 2015, $76,1039$.

[19] P. Trens, N. Tanchoux, A. Galarneau, D. Brunel, B. Fubini, E. Garrone, F. Fajula, F. Di Renzo. Langmuir 2005, 21, 8560 .

[20] K.S.W. Sing, J.D. Madeley. J Appl Chem 1954, 4, 365.

[21] M.A. Meyers, K.K. Chawla, Mechanical Behavior of Materials, $2^{\text {nd }}$ edition, Cambridge University Press, Cambridge, UK 2009.

[22] A. Bergander, L. Salmén. J Mater Sci 2002, 37, 151.

[23] P. Navi, V. Pittet, C. J. G. Plummer. Wood Sci Technol 2002, 36, 447.

[24] G. I. Mantanis, R. A. Young, M. Rowell. Holzforschung 1994, 48, 480.

[25] B. Clair, B. Thibaut, J. Sugiyama. J Wood Sci 2005, 51, 218.

[26] S. Lequin, D. Chassagne, T. Karbowiak, J.-P. Bellat. J Agric Food Chem 2013, 61, 5391.

[27] Y. Yang, F. Zhang. Ultrason Sonochem 2008, 15, 308.

[28] J. Domínguez-Robles, T.Tamminen, T. Liitiä, M. S. Peresin, A. Rodríguez, A.-S. Jääskeläinen. Int J Biol Macromol 2018, 106, 979.

[29] R. Hosseinpourpia, S. Adamopoulos, C. Mai. Wood Sci Technol 2016, 50, 165.

[30] T. Yang, H. Zhou, E. Ma, J. Wang. Results in Physics 2018, 10, 61.

[31] Y. Nishiyama, P. Langan, H. Chanzy. J Am Chem Soc 2002, 124, 9074.

[32] T. C. F. Gomes, M. S. Skaf. J Comput Chem 2012, 33, 1338.

[33] R.C. Pettersen, in The Chemistry of Solid Wood (Ed: R. Rowell), American Chemical Society,

Washington, DC, USA 1984, Ch. 2.

[34] A.P. Heiner, O. Teleman. Langmuir, 1997. 13, 511.

[35] M. D. Smith, B. Mostofian, X. Cheng, L. Petridis, C. M. Cai, C. E. Wyman, J. C. Smith. Green Chem. 2016. 18,1268

[36] W. M. Goldmann, J. Ahola, M. Mikola, J. Tanskanen, Sep Purif Technol 2019, 209, 826.

[37] S. M. Aguilera-Segura, F. Di Renzo, T. Mineva, J Mol Model 2018, 24, 292.

[38] M. J. Abraham, T. Murtola, R. Schulz, S. Pall, J. C. Smith, B. Hess, E. Lindahl. SoftwareX, 2015. 1-2, 19.

[39] H. Bekker, H. J. C. Berendsen, E. J. Dijkstra, S. Achterop, R. Vondrumen, D. Vanderspoel, A. Sijbers, H. Keegstra, M. K. R. Renardus, in Physics Computing '92 (Eds: R. A. De Groot, J. Nadrchal) World Scientific Publishing, Singapore 1993, p. 252.

[40] H. J. C. Berendsen, D. van der Spoel, R. van Drunen. Comput Phys Commun 1995. 91, 43.

[41] D. Van Der Spoel, E. Lindahl, B. Hess, G. Grienhof, A. E. Mark, H. J. Berendsen. J Comput Chem 2005. 26, 1701 .

[42] S. Páll, M. J. Abraham, C. Kutzner, B. Hess, E. Lindahl, in Solving Software Challenges for Exascale (Eds: S. Markidis, E. Laure) Springer International Publishing, Cham, Switzerland 2015, p. 3.

[43] W. L. Jorgensen, J. Chandrasekhar, J. D. Madura, R. W. Impey, M. L. Klein. J Chem Phys 1983. 79.

926.

[44] T. J. Dick, J. D. Madura, Annu Rep Comput Chem 2005, 1, 59.

[45] P. Mark, L. Nilsson. J Phys Chem A, 2001, 10, 9954.

[46] O. Guvench, S. N. Greene, G. Kamath, J. W. Brady, R. M. Venable, R. W. Pastor, A. D. MacKerell. J Comput Chem 2008. 29, 2543.

[47] O. Guvench, E. Hatcher, R. M. Venable, R. W. Pastor, A. D. MacKerell. J Chem Theory Comput 2009, $5,2353$.

[48] L. Petridis, J. C. Smith, J Comput Chem 2009, 30, 457.

[49] D. van der Spoel, P. J. van Maaren, C. Caleman, Bioinformatics 2012, 28, 752. 


\section{WILEY-VCH}

The table of contents entry should be 50-60 words long and should be written in the present tense and impersonal style (i.e., avoid we). The text should be different from the abstract text.

Synergistic effects of mixed solvents on properties of composite materials are observed through the study of sorption of water-ethanol solutions in lignocellulose, a natural model composite. Non-linear effects of solution composition on absorption, viscoelastic properties and cohesion of poplar wood are investigated and modelled by molecular dynamics.

Keyword: Lignocellulose swelling by mixed solvents

S. M. Aguilera-Segura, J. Bossu, S. Corn, P. Trens, T. Mineva, N. Le Moigne*, F. Di Renzo*

Synergistic sorption of mixed solvents in wood cell walls: experimental and theoretical approach

ToC figure ((Please choose one size: $55 \mathrm{~mm}$ broad $\times 50 \mathrm{~mm}$ high or $110 \mathrm{~mm}$ broad $\times 20 \mathrm{~mm}$ high. Please do not use any other dimensions))

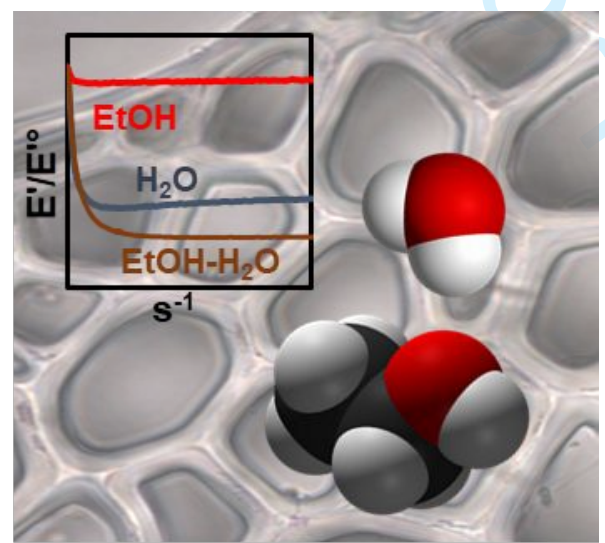

